\title{
Study of Influence of Alloying Elements on Strength and Thermal Resistance of Electric Engineering Aluminum Alloys
}

Viktor A. Berngardt*a,b, Tatyana N. Drozdova a,b, Tamara A. Orelkina ${ }^{a}$, Vladimir P. Zhereb and Olga V. Yakivyuk ${ }^{\mathrm{a}}$ ${ }^{a}$ Siberian Federal University 79 Svobodny, Krasnoyarsk, 660041, Russia ${ }^{b}$ «RUSAL ETC»LLC 37/1 Pogranichnikov Str., Krasnoyarsk, 660111, Russia

In the article a comparison analysis of $\mathrm{Zr}, \mathrm{Fe}$ and rare-earth metals (REM) influence on the structure and properties of deformable semi-finished products from aluminium alloys was investigated. It was established that to achieve properties of wire rod, demanded by ASTM B94105 , the less $\mathrm{Zr}$ content is needed in compare with REM. High temperature experiments of Al-Zr-Fe $u$ Al-REM alloys were performed to find more perspective alloying elements for the heat resistant wire production.

Keywords: wire rod, aluminium alloys, ASTM B941-05 standard, specific electric resistance, high temperature strength, heat resistant wire.

Citation: Berngardt V.A., Drozdova T.N., Orelkina T.A., Zhereb V.P., Fedorova O.V. Study of influence of alloying elements on strength and thermal resistance of electric engineering aluminum alloys, J. Sib. Fed. Univ. Eng. technol., 2016, 9(6), 872-879. DOI: 10.17516/1999-494X-2016-9-6-872-879.

(C) Siberian Federal University. All rights reserved

* Corresponding author E-mail address: berngardt19@mail.ru 


\title{
Исследование влияния легирующих элементов \\ на прочность и термостойкость алюминиевых сплавов электротехнического назначения
}

\author{
В.А. Бернгардт ${ }^{\mathrm{a}, \boldsymbol{\sigma}}$, Т.Н. Дроздова ${ }^{\mathrm{a}, \boldsymbol{\sigma}}$, \\ Т.А. Орелкина ${ }^{\text {a }, ~ В . П . ~ Ж е р е б ~}{ }^{\text {a }, ~ О . В . ~ Ф е д о р о в а ~}{ }^{a}$ \\ ${ }^{a}$ Сибирский федеральнылй университет \\ Россия, 660041, Красноярск, Свободный, 79 \\ ${ }^{\sigma} О О О$ «РУСАЛ ИТЦ» \\ Россия, 660111, Красноярск, Пограничников, 37/1
}

В статье проведен сравнительный анализ влияния ииркония, железа и РЗМ на структуру и свойства деформированных полуфабрикатов из алюминиевых сплавов. Установлено, что для достижения свойств катанки, заданных в ASTM B941-05, требуется на порядок меньше циикония по сравнению с РЗМ. Проведены высокотемпературные испытания сплавов $\mathrm{Al}-\mathrm{Zr}-\mathrm{Fe}$ u Al-PЗМ для поиска наиболее перспективных легирующих элементов для производства термостойких проводов.

Ключевые слова: катанка, алюминиевые сплавы, требования ASTM B941-05, удельное электрическое сопротивление, жаропрочность, термостойкие провода.

\section{Введение}

Электротехническая промышленность в современных условиях ориентирована на использование электропроводных материалов, которые сохраняют высокую прочность при эксплуатационных нагревах. Для решения этой задачи наиболее перспективным направлением является создание низколегированных алюминиевых сплавов с добавкой циркония. Выбор циркония обусловлен его способностью значительно увеличивать температурный порог рекристаллизации, что и позволяет проводам работать при повышенных температуpax.

Другим решением проблемы повышения жаропрочности алюминиевых сплавов служит легирование их редкоземельными металлами (РЗМ). Редкоземельные металлы, такие как Се и La, относятся к группе малорастворимых элементов, которые образуют с алюминием промежуточные фазы, обычно кристаллизующиеся в составе эвтектик. Эти фазы, как правило, тугоплавкие, а эвтектические температуры близки к температуре плавления алюминия, что положительно влияет на показатели жаропрочности.

Целью данной работы стало исследование влияния циркония, железа и РЗМ на структуру и свойства алюминиевой катанки электротехнического назначения.

\section{Методика эксперимента}

Объектом исследования была катанка из сплавов $\mathrm{Al}-(0,20-0,36) \% \mathrm{Zr}-(0,20-0,28) \% \mathrm{Fe}$ и $\mathrm{Al}-0,5-3,5$ \%Р3М. Катанку диаметром 9 мм из сплавов $\mathrm{Al}-\mathrm{Zr}-\mathrm{Fe}$ изготавливали на литейнопрокатном агрегате (ЛПА) с последующей сортовой прокаткой. Катанку из сплавов Al-PЗМ, где $\mathrm{P} 3 \mathrm{M}-\mathrm{Ce}+\mathrm{La}$, получали по технологии совмещенного литья и прокатки-прессования

$$
-873-
$$


(СЛИПП). Цирконий и РЗМ вводили в алюминий для повышения термостойкости, а железо для увеличения прочностных свойств деформированных полуфабрикатов. В конечном итоге физико-механические свойства катанки должны удовлетворять требованиям стандарта ASTM B941-05.

Удельное электрическое сопротивление (УЭС) катанки измеряли с помощью омметра «ВИТОК» в соответствии с ГОСТ 7229-76. Испытание на растяжение катанки и проволоки проводили на универсальной машине Walter+Bai AG LFM 400 kN.

Исследование микроструктуры сплавов осуществляли на микроскопе CarlZeiss Axio Observer A1m. Зеренную структуру образцов изучали после анодного оксидирования. Анодную пленку на образцах получали с помощью автоматической полировально-травильной установки ATM Kristall 620.

\section{Исследование структуры и свойств катанки сплавов системы Al-Zr-Fe и Al-P3M}

На первом этапе работы был проведен анализ зависимости удельного электрического сопротивления от концентрации циркония, железа и РЗМ в алюминиевых сплавах. Установлено, что с повышением концентрации циркония и РЗМ удельное электрическое сопротивление растет и наблюдается прямолинейная зависимость (рис. $1 a, \sigma)$. УЭС катанки из сплавов $\mathrm{Al}-(0,20-$ $0,36) \% \mathrm{Zr}-(0,20-0,28) \% \mathrm{Fe}$ не соответствует требованиям ASTM B941-05 и имеет значения 0,03147-0,03428 Ом·мм²/м. (табл. 1). Временное сопротивление разрыву данных сплавов находится в пределах 126-144 МПа (рис. 2a). Увеличение концентрации железа с 0,20 до 0,28 \% при одинаковом содержании циркония приводит к незначительному повышению уровня УЭС и росту временного сопротивления разрыву (рис. $2 a$ ). Повышение концентрации циркония в интервале $0,20-0,36 \%$ обеспечивает повышение предела прочности на $12 \%$. Относительное удлинение соответствует 7-12\% (рис. $3 a$ ).

Анализ механических свойств сплавов $\mathrm{Al}-(0,5-3,5)$ \% РЗМ показал, что для катанки исследуемых составов прочностные свойства находятся в пределах 119-162 МПа (рис. 2б), относительное удлинение - 20-27 \% (рис. 3б). Повышение концентрации РЗМ в исследуемом диапазоне дает прирост прочностных характеристик на 30 \%, пропорционально повышению предела прочности в сплавах снижаются пластические характеристики (табл. 3). Удельное

Таблица 1. Свойства катанки из сплавов системы $\mathrm{Al}-\mathrm{Zr}-\mathrm{Fe}$

\begin{tabular}{|c|c|c|c|c|}
\hline $\mathrm{Zr}$, масс ., \% & $\mathrm{Fe}$, масс., \% & $\sigma_{\mathrm{B}}, \mathrm{M \Pi а}$ & $\delta, \%$ & $\rho_{20}, \mathrm{OM} \cdot \mathrm{MM}^{2} / \mathrm{M}$ \\
\hline 0,20 & 0,20 & 126 & 10 & 0,03147 \\
\hline 0,20 & 0,28 & 144 & 12 & 0,03180 \\
\hline 0,27 & 0,28 & 143 & 7 & 0,03296 \\
\hline 0,29 & 0,20 & 140 & 8 & 0,03327 \\
\hline 0,33 & 0,20 & 141 & 9 & 0,03349 \\
\hline 0,36 & 0,20 & 140 & 9 & 0,03428 \\
\hline \multicolumn{2}{|c|}{ Требования ASTM В941-05 } & 120 & 8 & $\mathbf{0 , 0 2 8 5}$ \\
\hline
\end{tabular}


электрическое сопротивление катанки из сплавов Al-(0,5-3,5) \%РЗМ составляет 0,02614$0,02902 \mathrm{OM} \cdot \mathrm{Mm}^{2} / \mathrm{M}$, что соответствует требованиям ASTM B941-05, за исключением сплава Al-3,5 \%P3M.

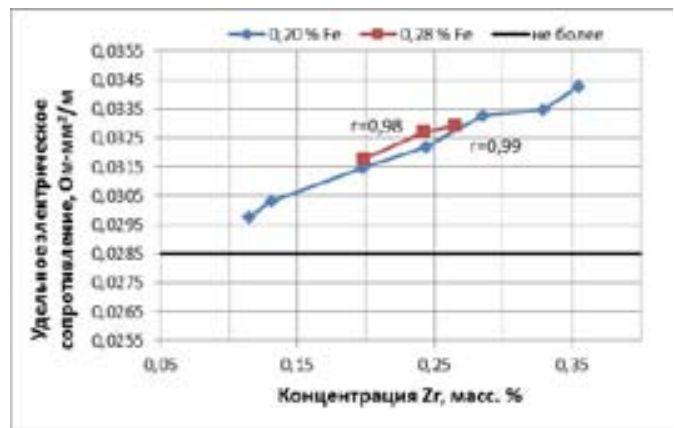

a

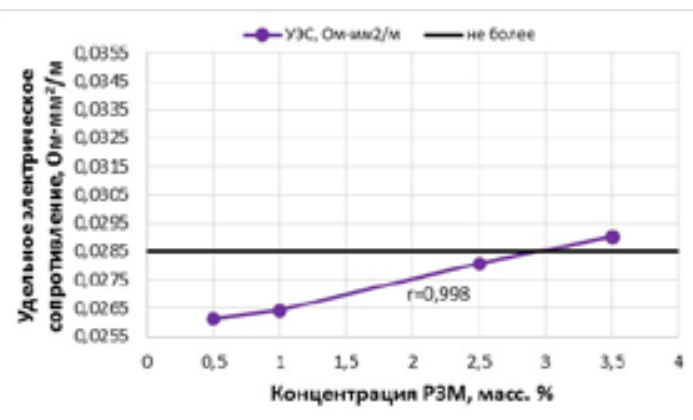

6

Рис. 1. Зависимость удельного электрического сопротивления от концентрации легирующих элементов сплавов: a - Al-Zr-Fe; б - Al-P3M

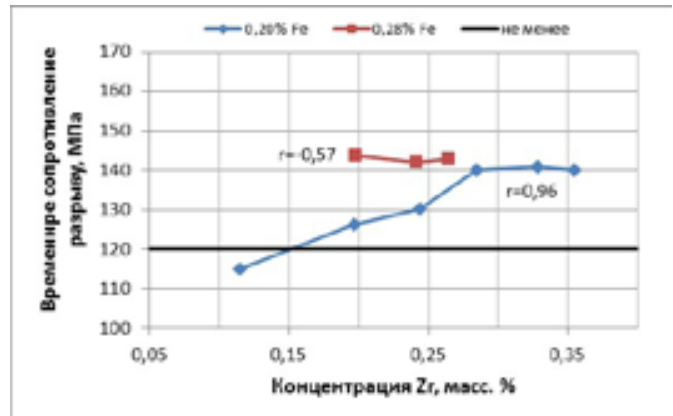

a

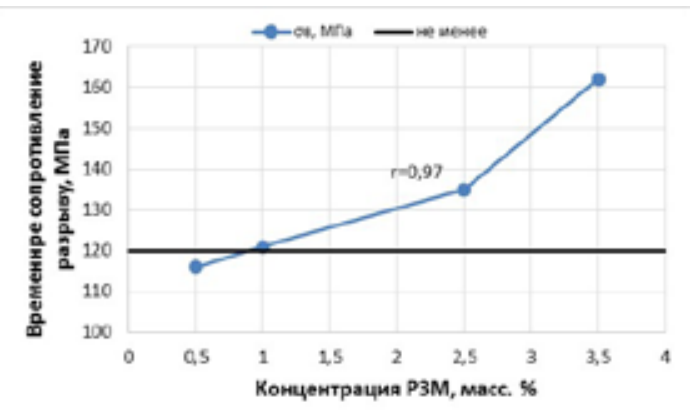

6

Рис. 2. Зависимость временного сопротивления разрыва от концентрации легирующих элементов сплавов: a - Al-Zr-Fe; б - Al-P3M

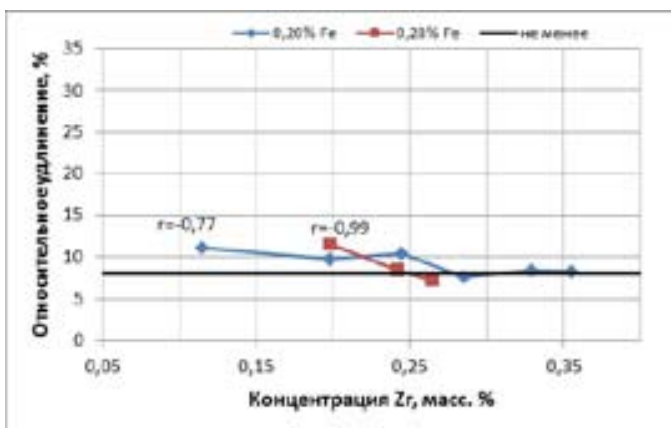

a

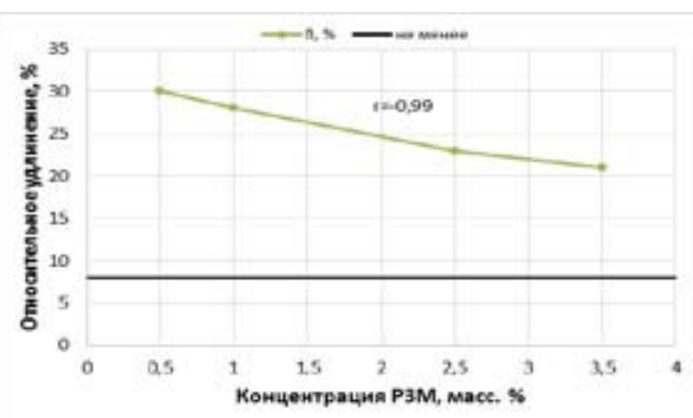

6

Рис. 3. Зависимость относительного удлинения от концентрации легирующих элементов сплавов: a - Al-Zr-Fe; б - Al-P3M 
Микроструктура образцов катанки в поперечном сечении состоит из зерен пересыщенного цирконием $\alpha$-твердого раствора на основе алюминия и мелких железосодержащих частиц избыточных фаз, расположенных по границам дендритных ячеек и ориентированных в направлении прокатки; часть включений образует строчечность (рис. 4a, в). Повышение концентрации циркония в сплавах приводит к уменьшению размера зерна (рис. 42), повышение концентрации железа - к увеличению объемной доли железосодержащих фаз (рис. 4в).

Микроструктура исследуемых прутков, изготовленных СЛИПП, представлена зернами $\alpha$-твердогоа и макронеоднородностью в виде строчечного расположения эвтектических колоний $\left(\alpha+\mathrm{Al}_{4} \mathrm{Me}\right)$, имеющих пластинчатое строение (рис. 5). Увеличение концентрации легирующих элементов усиливает неоднородность в структуре прутков и приводит к росту объемной доли эвтектики. Значительное легирование сплавов, до 3,5 \% РЗМ, приводит к грубой строчечной структуре по всему объему прутка (рис. 52).

Достижение требований ASTM B941-05 по удельному электрическому сопротивлению в катанке из малолегированных цирконием алюминиевых сплавов возможно после воздействия термической обработки. Известно положительное влияние на понижение удельного электрического сопротивления гетерогенизирующего отжига Al-Zr сплавов, основным процессом которого является снижение концентрации легирующих элементов в твердом растворе за счет его распада с выделением дисперсных частиц метастабильной фазы $\mathrm{Al}_{3} \mathrm{Zr}$ [1-4].

Одинарный отжиг по исследуемым режимам в работах $[1,3,4]$ не обеспечил необходимый уровень УЭС. Было показано, что для снижения УЭС катанки при одноступенчатом отжиге необходимо использовать длительные выдержки. В ранее проведенных работах $[1,3]$ для повышения производительности процесса термической обработки и более существенного сниже-

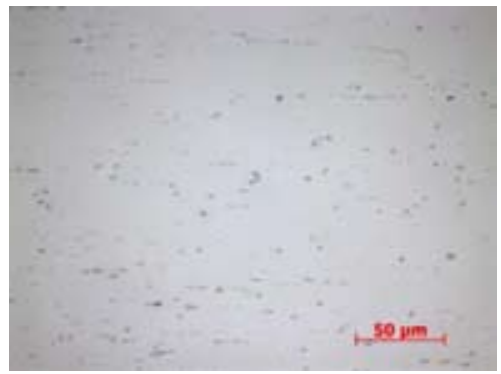

a

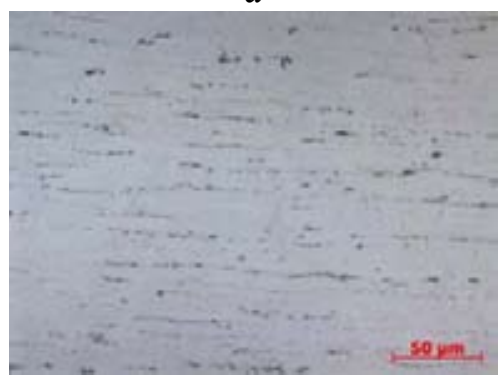

B

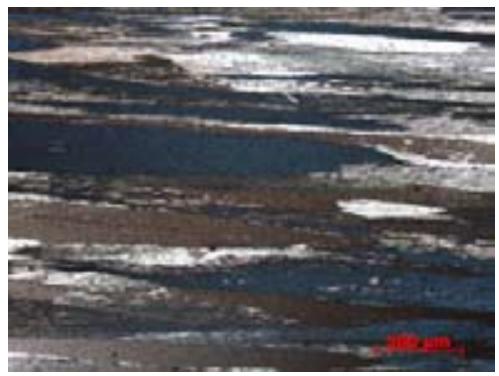

6

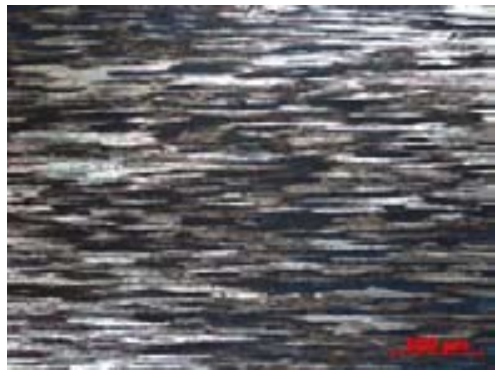

$\Gamma$

Рис. 4. Микроструктура катанки сплавов: а, б - Al-0,27 \% Zr- $0,20 \% \mathrm{Fe}$; в - $\mathrm{Al}-0,27 \% \mathrm{Zr}-0,28 \% \mathrm{Fe}$,

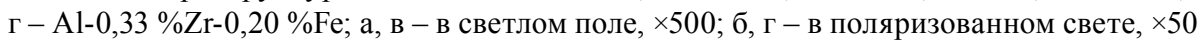




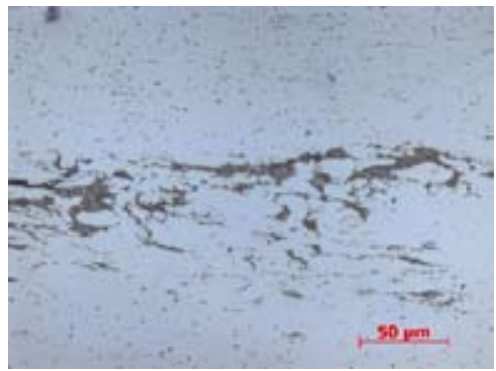

a

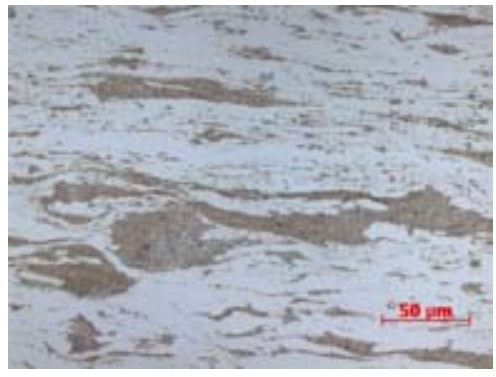

B

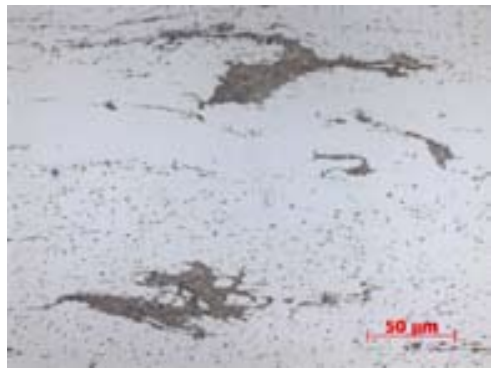

6

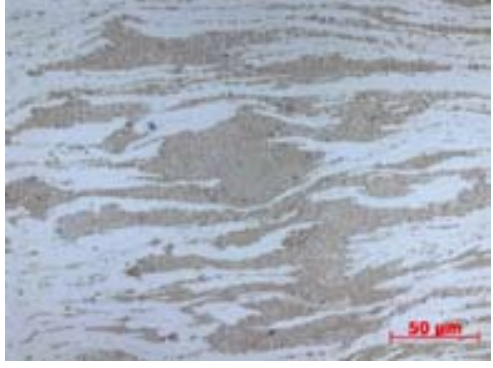

$\Gamma$

Рис. 5. Микроструктура прутков, полученных СЛИПП, из сплавов Аl-P3М, ×500: a - Al-0,5 \% Р3М; б - Al-1,0 \% P3M; в - Al-2,5 \% P3M; г-Al-3,5 \% P3M

Таблица 2. Режимы отжига и свойства катанки сплава $\mathrm{Al}-0,27 \mathrm{Zr}-0,28 \mathrm{Fe}$

\begin{tabular}{|c|c|c|c|c|}
\hline Отжиг & Режим отжига & $\rho_{20}, \mathrm{Oм}^{\prime} \mathrm{MM}^{2} / \mathrm{M}$ & $\sigma_{\mathrm{B}}, \mathrm{MПа}$ & $\delta, \%$ \\
\hline Одинарный & $350^{\circ} \mathrm{C}, 48$ ч & 0,03024 & 135 & 19 \\
\hline Ступенчатый & $350{ }^{\circ} \mathrm{C}, 48$ ч + вторая ступень & 0,02803 & 134 & 23 \\
\hline Одинарный & $400^{\circ} \mathrm{C}, 12$ ч & 0,02959 & 127 & 23 \\
\hline Ступенчатый & $400{ }^{\circ} \mathrm{C}, 12$ ч + вторая ступень & 0,02790 & 127 & 25 \\
\hline \multicolumn{2}{|c|}{ Требования ASTM В941-05 } & 0,0285 & 120 & 8 \\
\hline
\end{tabular}

ния УЭС катанки из малолегированных сплавов системы $\mathrm{Al}-\mathrm{Zr}$ рекомендовано использовать ступенчатый отжиг.

После проведения ступенчатого гетерогенизирующего отжига УЭС катанки сплавов $\mathrm{Al}-\mathrm{Zr}-\mathrm{Fe}$ составляет 0,02790-0,02803 Ом $\cdot \mathrm{Mм}^{2} / \mathrm{M}$, прочность - 127-134 МПа, пластичность 23$25 \%$. Измеренные значения временного сопротивления разрыву и удельного электрического сопротивления катанки, отожженной по режимам двухступенчатого отжига, удовлетворяют требованиям международного стандарта ASTM B 941-05 (табл. 2). После проведения ступенчатого отжига сплавы с цирконием по УЭС и прочности сопоставимы со сплавом Al-2,5 \%РЗМ.

\section{Исследование термостойкости сплавов Al-Zr-Fe и Al-P3M}

Для определения термостойкости катанки проводили высокотемпературные испытания на растяжение. Испытание на растяжение при повышенной температуре $\left(150{ }^{\circ} \mathrm{C}\right)$ сплавов 
Таблица 3. Свойства катанки из сплавов системы Al-P3М при комнатной и повышенной температурах испытания

\begin{tabular}{|c|c|c|c|c|c|}
\hline \multirow{2}{*}{ Сплав } & \multicolumn{3}{|c|}{ Испытания при $t_{\text {ком }}$} & \multicolumn{2}{|c|}{ Испытания при $\mathrm{t}=150^{\circ} \mathrm{C}$} \\
\hline & $\sigma_{\mathrm{B}}, \mathrm{MПа}$ & $\delta, \%$ & УЭС, Ом'мм $2 / \mathrm{M}$ & $\sigma_{\mathrm{B}}, \mathrm{MПа}$ & $\mathrm{K}_{\mathrm{H}}, \% *$ \\
\hline Al- $0,5 \% \mathrm{P} 3 \mathrm{M}$ & 119 & 27 & 0,02614 & 119 & 100 \\
\hline Al-1,0 \% & 129 & 24 & 0,02643 & 118 & 92 \\
\hline $\mathrm{Al}-2,5 \% \mathrm{P} 3 \mathrm{M}$ & 147 & 22 & 0,02807 & 119 & 81 \\
\hline Al-3,5 \%P3M & 172 & 20 & 0,02902 & 139 & 81 \\
\hline
\end{tabular}

*К

Таблица 4. Свойства катанки при комнатной и повышенной температурах испытания

\begin{tabular}{|c|c|c|c|c|c|}
\hline \multirow{2}{*}{ Сплав } & \multicolumn{3}{|c|}{ После отжига (испытания при $t_{\text {ком}}$ ) } & \multicolumn{2}{|c|}{ Испытания при $\mathrm{t}=230^{\circ} \mathrm{C}$} \\
\hline & $\sigma_{\mathrm{B}}, \mathrm{M \Pi а}$ & $\delta, \%$ & 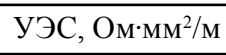 & $\sigma_{\mathrm{B}}, \mathrm{M \Pi а}$ & $\mathrm{K}_{\mathrm{H}}, \% *$ \\
\hline Al- $0,27 \% \mathrm{Zr}-0,28 \% \mathrm{Fe}$ & 136 & 26 & 0,0284 & 124 & 91 \\
\hline
\end{tabular}

$K_{\text {н }}, \%$ - остаточный коэффициент напряжения при нагреве.

Al-(0,5-3,5) \% РЗМ показало, что снижение предела прочности катанки происходит не более чем на $20 \%$ от первоначально измеренных значений (табл. 3), а при испытании катанки из сплава Al-0,27 \% Zr-0,28 \% Fe при температуре $230{ }^{\circ} \mathrm{C}$ предел прочности снизился всего на $10 \%$ (табл. 4).

\section{Выводы}

Сравнительный анализ деформированных полуфабрикатов электротехнического назначения позволил установить, что введение $0,5-2,5 \%$-ных дорогостоящих РЗМ в алюминий незначительно увеличивает УЭС, значения которого соответствуют требованиям ASTM B941-05. Легирование алюминиевых сплавов цирконием в количестве $0,20-0,36 \% \mathrm{Zr}$, что на порядок ниже, чем РЗМ, значительно повышает УЭС, которое существенно превышает требуемые значения стандарта. Для снижения удельного электрического сопротивления катанки, легированной цирконием, до требований ASTM B941-05 необходимо проводить гетерогенизирующий отжиг.

Повышение концентрации РЗМ в алюминии с 0,5 до 3,5 \% увеличивает значения временного сопротивления разрыву на 30 \%. В сплавах Al-Zr-Fe повышение концентрации Zr c 0,20 до 0,36 \% приводит к росту предела прочности катанки на $12 \%$. При этом относительное удлинение катанки, легированной РЗМ, в 2 раза выше.

Высокотемпературные испытания показали, что сплав $\mathrm{Al}-0,27 \% \mathrm{Zr}-0,28 \% \mathrm{Fe}$ сохраняет на $90 \%$ предел прочности при температуре $230{ }^{\circ} \mathrm{C}$, а сплавы, легированные РЗМ в количестве 1,0-3,5 \%, сохраняют прочностные свойства на 80-90\% только при температуре $150{ }^{\circ} \mathrm{C}$. Следовательно, легирование алюминия цирконием на порядок меньшей концентрацией, чем РЗМ, обеспечивает более высокую жаропрочность сплавам.

$$
-878-
$$


Анализ влияния легирующих элементов на свойства катанки из электротехнических алюминиевых сплавов показал, что цирконий является наиболее перспективным легирующим элементом для производства термостойких проводов.

\section{Список литературы}

[1] Бернгардт В.А., Дроздова Т.Н., Орелкина Т.А., Сидельников С.Б., Трифоненков Л.П., Фролов В.Ф., Сальников А.В., Федорова О.В. Разработка режимов отжига катанки из сплавов системы Al-Zr для достижения заданного комплекса свойств. Журнал СФУ. Техника и технологиu, 2014, 7(5), 587-595 [Berngardt V.A., Drozdova T.A., Orelkina T.A., Sidelnikov S.B., Trifonenkov L.P., Frolov V.F., Salnikov A.V., Fedorova O.V. Development of annealing conditions wire rod alloy of Al-Zr system to reach required properties. J. Sib. Fed. Univ. Eng. Technol., 2014, 7(5), 587-595 (in Russian)]

[2] Белов Н.А., Истомин-Кастровский В.В., Алабин А.Н. Влияние циркония на структуру и механические свойства малолегированных сплавов системы $\mathrm{Al}-\mathrm{Fe}-\mathrm{Si}$. Известия ВУЗов. Цветная металлургия, 2003, 4, 54-59 [Belov N.A., Istomin-Kastrovskiy V.V., Alabin A.N. Zirconium influence on structure and mechanical properties of low doped alloys of Al-Fe-Si system. Izvestiya VUZov. Tsvetnaya metallurgiya, 2003, 4, $54-59$ (in Russian)]

[3] Бернгардт В.А., Федорова О.В. Исследование влияния режимов термической обработки на структуру и свойства катанки из сплавов системы $\mathrm{Al}-\mathrm{Zr}$. Молодежь и наука: IX Всероссийская научно-техническая конференция с международным участием, 2013; http://conf.sfu-kras. ru/sites/mn2013/thesis/s007/s007-006.pdf [Berngardt V.A., Fedorova O.V. Investigation of influence of heat treatment conditions on structure and properties of alloys Al-Zr system, Molodezh i nauka: IX Vserossiyskaya nauchno-prakticheskaya konferentsiya s mezdunarodnym uchastiem, 2013; http://conf. sfu-kras.ru/sites/mn2013/thesis/s007/s007-006.pdf (in Russian)]

[4] Белов Н.А., Алабин А.Н., Прохоров А.Ю. Влияние отжига на электросопротивление и механические свойства холоднодеформированного сплава Al-0,6 \% (мас.) Zr. Цветные металльь, 2009, 10, 65-68 [Belov N.A., Alabin A.N., Prokhorov A.Yu. Annealing influence on resistivity and mechanical properties of cold deformed alloy Al-0,6 \% (mas.) Zr. Tsvetnye metally, 2009, 10, 65-68 (In Russian)] 